\title{
Monitoring training status using novel submaximal test
}

\author{
M.J Hofmijster ${ }^{1,2^{*}}$, G.J.J van de Plasse ${ }^{1}$, A.M.C van Beijsterveldt ${ }^{2}$, J.H Stubbe ${ }^{2,3}$ \\ From World's Leading Rowing Sport Science and Medicine Conference - "Improving Performance Naturally" \\ Marlow, UK. 22-25 January 2015
}

\section{Introduction}

Rowers in their first year of competition have a high risk of overtraining, caused by a disbalance in training load and recovery. A typical week in the rowing season consists of 5-8 training sessions, and many first year ("freshmen") rowers have little previous experience in competitive sports. The risk is further increased by the fact that personalization of training load is difficult and that coaches are often inexperienced. In this study we investigated whether a standardized submaximal exercise rowing test (SERT) can be used as a tool to monitor training status and as such can help to prevent overtraining.

\section{Methods}

For a period of four weeks, the weekly training load of members of one lightweight men's freshmen crew (eight rowers) was quantified by summating heart rate scores (Edwards, 1993). Rowers undertook the SERT on a rowing ergometer (Concept 2, USA) on a weekly basis. The SERT adapted from the LSCT (Lamberts, 2011) and yields values for power output at 70,80 and $90 \%$ of maximum heart rate, heart rate recovery (HRR, defined as the drop in heart rate in one minute after cessation of exercise) and rate of perceived exertion (RPE) on a $0-10$ point scale (Foster 2001).

\section{Results}

One participant dropped out because he showed signs of overtraining already at the start of the experiment. For the remaining seven rowers, training load was significantly higher in weeks 2 and 3 compared to weeks 1 and 4 $(\mathrm{P}<0.01)$. Consequently, these weeks were categorized as 'heavy weeks' (H) whereas weeks 1 and 4 were categorized as 'light to moderate' weeks (L). HRR was shown to be

\footnotetext{
* Correspondence: m.hofmijster@vu.nl

${ }^{1}$ Faculty of Human Movement Sciences, VU Amsterdam, the Netherlands
}

Full list of author information is available at the end of the article significantly lower during the heavy weeks (L: $53.8 \pm 8.48$, $\mathrm{H}: 50.6 \pm 6.50, \mathrm{P}<0.05)$, suggesting fatigue or inaccurate recovery. No differences were found in power values or RPE scores.

\section{Discussion}

Obtaining relevant information on training status of individual team members can prove to be difficult in crew rowing. This study indicates that a standardized training such as the SERT helps to monitor individual rowers, especially when HRR is obtained. A sudden drop in HRR is as an early warning sign and may lead a coach to adapt the training schedule. Furthermore, the participants rated the SERT with 3.8 on the $0-10$ RPE scale, indicating that the SERT is suitable to be performed on a frequent basis without interfering with the daily training. Future research should point out whether occurrence of overtraining would indeed be lower with frequent monitoring of training status.

\section{Authors' details \\ ${ }^{1}$ Faculty of Human Movement Sciences, VU Amsterdam, the Netherlands. ${ }^{2}$ Hogeschool van Amsterdam, Amsterdam, the Netherlands. ${ }^{3}$ TNO Life Style, Leiden, the Netherlands.}

Published: 11 August 2015

References

1. Lambert RP, Swart J, Noakes TD, Lambert MI: A novel submaximal cycle test to monitor fatigue and predict cycling performance. $\mathrm{Br} J$ Sports Med 2011, 45(10):797-804.

2. Edwards S: The heart rate monitor book. 1993.

3. Foster C, Florhaug J, Franklin J, Gottschall L, Hrovatin LA, Parker S, Doleshal P, Dodge C: A new approach to monitoring exercise training. J Strength Cond Res 2001, 15(1):109-115.

doi:10.1186/2052-1847-7-S1-O4

Cite this article as: Hofmijster et al:: Monitoring training status using novel submaximal test. BMC Sports Science, Medicine and Rehabilitation 2015 7(Suppl 1):04.
() Biomed Central

(c) 2015 Hofmijster et al. This is an Open Access article distributed under the terms of the Creative Commons Attribution License (http://creativecommons.org/licenses/by/4.0), which permits unrestricted use, distribution, and reproduction in any medium, provided the original work is properly cited. The Creative Commons Public Domain Dedication waiver (http://creativecommons.org/ publicdomain/zero/1.0/) applies to the data made available in this article, unless otherwise stated. 